Л. С. Ёлгина, И. М. Очиров. Философские основы научного мировоззрения в контексте личностно ориентированного образования

Научная статья

УДК 37.013

DOI: $10.18101 / 1994-0866-2021-2-33-41$

\title{
ФИЛОСОФСКИЕ ОСНОВЫ НАУЧНОГО МИРОВОЗЗРЕНИЯ В КОНТЕКСТЕ ЛИЧНОСТНО ОРИЕНТИРОВАННОГО ОБРАЗОВАНИЯ
}

\author{
(C) Ёлгина Лариса Сергеевна \\ кандидат философских наук, доцент, \\ Бурятский государственный университет имени Доржи Банзарова \\ Россия, 670000, г. Улан-Удэ, ул. Смолина, 24a \\ elgina66@bk.ru \\ (C) Очиров Иннокентий Михайлович \\ старший преподаватель физической культуры, \\ Бурятский государственный университет имени Доржи Банзарова \\ Россия, 670000, г. Улан-Удэ, ул. Смолина, 24а \\ ochirov1966@gmail.ru
}

Аннотация. В статье рассматривается научное мировоззрение как духовное, интегративное, глубоко личностное образование, способное ориентировать человека на перспективу творческого созидания, на выбор достойного образа жизни, осмысление собственной значимости. Научное мировоззрение создает необходимую основу для проектирования модели деятельности индивида, помогает ему осознать цели и смысл жизни, осуществить поиски своего места в обществе, реализовать личностные интересы и способности.

Необходимость рассмотрения данной проблемы обусловлена рядом объективных факторов и тенденций. Авторы статьи рассматривают личностно-ориентированное образование как основу права выбора предметного содержания, способов деятельности, обеспечивающих гуманизацию образования, реализацию подлинно демократических основ, свободу морального выбора. Все это создает новые предпосылки для становления мировоззренческих убеждений, выработки устойчивых жизненных ориентиров. Раскрытие индивидуальных возможностей и на этой основе формирование общечеловеческих ценностей, становление высоконравственных качеств личности - основная задача личностно ориентированного образования.

Ключевые слова: личность, мировоззрение, личностно ориентированное образование, гуманистическая направленность, ценности, идеалы, жизненные ориентиры

\section{Для цитирования}

Ёлгина Л. С., Очиров И. М. Философские основы научного мировоззрения в контексте личностно ориентированного образования // Вестник Бурятского государственного университета. Философия. 2021. Вып. 2. С. 33-41.

Проблемы образования в современном обществе приобретают общемировое значение: не случайно ХХІ век объявлен ЮНЕСКО «веком образования». С одной стороны, возрастает роль образования в жизни современного общества, с другой - растет недовольство существующим традиционным образованием.

Современный образованный человек - это человек, обладающий мировоззренческими идеями, системой ценностных ориентаций, которые определяют 
общий подход к различным фактам и событиям, умение критически мыслить, оценивать явления окружающего мира с нравственных позиций, применять изученное и создавать новое. Образование, в частности личностно ориентированное, - это целенаправленный процесс и результат формирования мировоззрения, познавательных способностей, развитие мышления и чувств [1].

Основными категориями мировоззрения являются «мир» и «человек». Они детализируются сквозь призму многообразных отношений человека к природе, обществу, другим людям, самому себе. Эти мировоззренческие категории всегда имеют социокультурную направленность и в значительной степени представляют, с одной стороны, схему рационального объяснения мира, с другой - структуру личностного осмысления и переживания объективной реальности.

Содержание мировоззренческих категорий претерпевает постоянное изменение по мере развития социально-исторической практики и научного познания. В этом плане мировоззрение следует рассматривать как постоянно развивающийся способ понимания и духовно-практического освоения мира. Способ осмысления мира определяется структурой мышления, его категориальным аппаратом.

Мировоззрение человека складывается под воздействием различных факторов объективного и субъективного характера, среди которых социальные условия, образование, производственные отношения, средства массовой информации и др. Мировоззренческое становление личности «начинается с детства (с процесса начала социализации ребенка, приобщения его к жизни общества) и продолжается, совершенствуясь, по существу, в течение всей жизни. Оно определяет жизненную позицию, реализуясь в характере трудовой и социальной активности, в семье, в обществе» [7].

Н. Н. Моисеев определяет мировоззрение как один из основных элементов, который дает представление человеку о Мире, Космосе и Разуме и его месте в этом мире. Мировоззрение представляет собой систему обобщенных взглядов «на объективный мир и на место человека в нем, на отношение людей к окружающей их действительности и самим себе, а также обусловленные этими взглядами их убеждения, идеалы, принципы познания и деятельности [4].

Мировоззрение как результат превращения социальных принципов и норм в логику индивидуального мышления и императивы поведения человека регулирует отношения между людьми, между знанием и практическим опытом. В связи с этим в новых условиях важнейшим фактором духовно-нравственного развития, формирования социальной и трудовой активности являются гуманистические идеи, представление права морального выбора, сферы творческой деятельности. Поэтому становление личности, ее научного мировоззрения требует превращения системы научных знаний в глубокие убеждения. Рассматриваемый процесс может быть осуществлен успешно на основе научного осмысления сущности природных и социальных явлений, формирования эмоционально-ценностного отношения к ним [3].

И. С. Кон справедливо подчеркивает, что «юношеский возраст особенно предрасположен к восприятию и осознанию мировоззренческих идей, так как именно в это время созревают когнитивные и личностные предпосылки» [2, 
Л. С. Ёлгина, И. М. Очиров. Философские основы научного мировоззрения в контексте личностно ориентированного образования

с. 82]. Он рассматривает в качестве отличительных признаков формирования мировоззрения у студентов нравственную зрелость, четкость жизненной позиции, их профессиональное самоопределение.

Формирование взглядов, устойчивых убеждений, идеалов составляет основное содержание процесса становления научного мировоззрения личности. В соответствии с принципом научности образовательные учреждения должны обеспечивать усвоение учащимися научно обоснованного содержания образования, раскрывающего закономерности развития природы и общества. В процессе обучения и воспитания должно осуществляться научное истолкование рассматриваемых явлений, уяснение заключенных в них причинно-следственных, диалектических связей. При этом важно побуждать студентов к выяснению возникающих у них вопросов, развивать их познавательный интерес и активность.

Основу всей системы мировоззренческого воспитания составляет положение о связи теории с практикой. Этот принцип находит отражение в содержании, методах и формах организации образовательного процесса. Принцип связи теории с практикой обязывает излагать систему научных знаний как обобщенные результаты социально-исторической практики человечества, раскрывать глубокую диалектическую связь различных областей науки с практической деятельностью. Важнейшим средством реализации связи теории с практикой является трудовая, технологическая направленность образовательного процесса. Технологическое образование способствует осознанному усвоению программного материала, показывает, как теоретические знания используются в производстве.

Формирование мировоззрения представляет собой многоаспектный и многогранный процесс, его можно рассматривать как саморазвивающуюся систему, которая функционирует на основе указанных принципов. По нашему мнению, опора на данные принципы позволит обеспечить гуманистическую, личностноориентированную направленность, полноту, диалектичность процесса становления целостного мировоззрения учащихся.

Следует иметь в виду, что мировоззренческое образование представляет собой саморазвивающуюся систему, между компонентами которой существуют специфические связи. Приведение этих частей в определенную иерархию, структуру с учетом функциональных особенностей и зависимостей составляет предмет системного подхода. В связи с этим сегодня актуальной становится проблема систематизации мировоззренческой подготовки, трансформации ее в разнообразное образовательно-воспитательное пространство, обладающее личностноориентированной направленностью. Построение такой системы должно осуществляться в соответствии с требованиями социального, экономического, культурного прогресса на основе принципа единства, всеобщей связи и развития явлений объективной реальности. При этом необходимо учитывать логические связи между компонентами системы, их функциональные зависимости. С учетом степени взаимосвязи этих компонентов, соподчиненности элементов в каждом из компонентов, их познавательной значимости, воспитательной результативности осуществляется упорядочение их в органическую совокупность и тем самым образование из них целостной системы. Созданная целостность приобретает новые 
качественные познавательные характеристики, социально-личностную направленность, интегративные свойства.

Большую роль в повышении эффективности становления мировоззренческих взглядов и убеждений играет осуществление комплексного подхода. Этот принцип предусматривает охват всех элементов мировоззренческого воспитания, которые взаимосвязаны и каждый из которых приобретает комплексный характер: цель и задачи мировоззренческой подготовки, содержание, формы и методы формирования мировоззрения, актуализация мотивов, ведущих факторов в работе по формированию мировоззрения, организация деятельности с учетом личностных особенностей учащихся, анализ достигнутых результатов.

Мировоззрение новой эпохи - это ориентация на качественно новый уровень мышления, систему знаний и отношение к ним, что обеспечивает высокую профессиональную, технологическую, коммуникативную культуру, экологическое сознание, нравственную ответственность за свою судьбу, за судьбу своей страны. Становление мировоззрения личности на современном этапе предусматривает осознание индивидом того, что устойчивость развития общества означает наращивание экономической мощи, преодоление социальных, национальных конфликтов, соблюдение баланса между природой, технологией и человеком.

Одним из важнейших предпосылок формирования научного мировоззрения учащихся выступает осознанное усвоение ими ведущих мировоззренческих идей, поэтому очень важное значение в решении поставленной проблемы имеет выявление идей и понятий мировоззренческого характера в учебных курсах. С этих позиций удачный подход осуществляет Р. М. Рогова. Автор выделяет ряд мировоззренческих идей в предметах гуманитарного цикла:

- человек в системе новых общественно-экономических (в т. ч. рыночных) отношений;

- социальные, политические права и обязанности, реализация свободы личности, ее интересов, развитие демократии и моральной ответственности каждого человека перед обществом, перед самим собой;

- национальное, многонациональное и интернациональное в области образования, культуры народа;

- человек и духовный мир: общечеловеческие, общегражданские ценности, эстетические идеалы, прогресс общества и приоритеты личности и др. [5].

Анализ современных научных источников (М. Н. Берулава, Е. В. Бондаревская, О. С. Газман, В. А. Караковский, Л. Н. Куликова, Р. М. Рогова, В. В. Сериков, И. С. Якиманская и др.), посвященных проблеме гуманизации образования, дает основание считать, что в российской науке есть своя теоретикометодологическая база, что позволяет целенаправленно проводить исследования значительного количества частных аспектов гуманистически ориентированного образовательного процесса, обеспечить эффективное внедрение полученных результатов в школьную практику. С позиций гуманистического подхода становление личности, ее мировоззренческой позиции рассматривается как процесс саморазвития индивида. При этом человек сам является творцом собственной судьбы, осуществляет моральный выбор и несет ответственность за него. 
Л. С. Ёлгина, И. М. Очиров. Философские основы научного мировоззрения в контексте личностно ориентированного образования

Одним из основных направлений реализации гуманистической парадигмы развития индивида выступает осуществление личностно ориентированного образования. В условиях личностно ориентированного образования становление научного мировоззрения понимается как непрерывное развитие личностноценностных отношений учащихся к окружающему миру, очеловечивание процесса научного познания в синтезе с раскрытием и совершенствованием творческого потенциала личности. Развитие мировоззренческих взглядов и убеждений ученика осуществляется на основе интеграции представлений о взаимосвязи и взаимозависимости естественно-научного, экологического, технологического, эстетического, социального и других аспектов реального мира. Именно этот процесс отражает все многообразие самоизменения, самостроения и самовыражения человека.

Следует отметить, что стремление активизировать процесс мировоззренческого становления учащихся за счет различных организационных мероприятий, направленных на восприятие информации, применение активных форм обучения не всегда приводит к кардинальному решению проблемы, так как не затрагивает глубинной сущности самой личности, ее потребностей, интересов, опыта. Отсюда следует вывод: не оказывают существенного влияния на установку индивида знания, которые не приобрели индивидуально-личностного смысла. Это могут быть знания излишне теоретического характера или знания, преподнесенные без соответствующей аргументации и доказательности. Поэтому личностноориентированный подход, реализуемый во всех звеньях непрерывного мировоззренческого образования, должен быть обращен к личности обучающегося, к созданию условий для его саморазвития, становления целостного мировоззрения. Это означает, что сам процесс образования в системе мировоззренческого становления личности должен быть ориентирован на целостное развитие взглядов, убеждений, ценностных отношений, духовных и познавательных способностей, на привитие навыков саморегуляции, на самоопределение и самореализацию студента. В центре концепции формирования научного мировоззрения учащихся лежит вера в субъектный опыт человека, а также умение открывать в себе внутренний потенциал, самостоятельно проектировать и реализовывать направления личностного творческого роста. Мировоззренческое становление личности определяется прежде всего за счет развития внутренних ресурсов, сущности человека.

В условиях личностно ориентированного образования знания приобретают индивидуально-личностный характер и оказывают существенное влияние на становление научного мировоззрения. Включаясь в разнообразные формы и виды самостоятельной деятельности, студенты самообучаются, при этом задача преподавателя состоит в создании благоприятных условий для раскрытия их личностного потенциала. Особая роль в осуществлении педагогической поддержки придается личности педагога-фасилитатора, функция которого заключается в оказании профессиональной помощи в процессе творческого самостановления личности, ее мировоззренческой направленности, ценностных ориентиров.

Значительными возможностями в становлении мировоззрения обладают используемые в учебно-познавательном процессе методы и формы организации общественно полезной, трудовой, природоохранной деятельности. Так, ознаком- 
ление учащихся с основными способами технологического освоения действительности, с организацией и управлением трудом и производством, экологизацией всех сфер социальной практики на экскурсиях, факультативных занятиях, спецкурсах, практикумах, практических занятиях расширяет границы мировоззренческих поисков, развивает стремление выработать свое видение мира, свое отношение к нему. При этом предметы и явления окружающей реальности приобретают для студентов глубоко личностный смысл. Они осознают важность созидательного труда человека, проблемы взаимодействия общества и природы как основы производства материальных и духовных ценностей.

Познавая различные аспекты внешнего мира, человек в сущности изучает и глубинные пласты своей природы, своего внутреннего мира, духовности. Сегодня особенно необходима духовность как высшая ступень человеческого сознания в соответствии с законами Природы и Космоса. При этом важно сделать общение людей, их воздействие друг на друга процессом, свободным от национальных конфликтов, ненависти, отчужденности. Именно в этом состоит, на наш взгляд, сущность гуманистических идей, которые определяют цели и задачи мировоззренческого образования, а также содержание и формы совместной практической деятельности педагога и учащихся.

Научное мировоззрение имеет гуманистическую направленность. Осмысливая генезис мировоззрения в ходе социально-исторического развития человеческого общества, следует отметить, что в разные эпохи гуманизм рассматривался учеными как мировоззренческая, нравственная категория. На разработку проблем становления мировоззрения личности большое влияние оказали гуманистические идеи русских ученых 19-го столетия: К. Д. Ушинского, П. Ф. Каптерева, П. Ф. Лесгафта, Н. И. Новикова, Л. Н. Толстого и др.

Гуманистический подход в педагогической науке как самостоятельное направление возник в 50-60-х гг. XX в. Его представителями являются К. Роджерс, Г. Олпорт, А. Маслоу, Р. Мэй, С. Коэн и др.

Анализ научной литературы позволяет утверждать, что личностноориентированное, гуманистическое образование выступает важным фактором становления мировоззренческих взглядов и убеждений. Его осуществление предусматривает:

- признание личности обучающегося основным субъектом образовательного процесса;

- постановку цели обучения - развитие индивидуальных способностей и возможностей обучающегося;

- определение комплекса средств, способствующих реализации поставленной цели через выявление и развитие личностного опыта обучающегося.

В ходе личностно ориентированного образования особое внимание уделяется индивидуальности, самобытности личности студента, особенностям его субъективного опыта, восприятия, осмысления учебного материала.

Вместе с тем личностно ориентированное образование предполагает единство таких факторов, как мотивационный, эмоционально-ценностный, интеллектуальный и социально-практический. Реализуемые во взаимодействии, они составляют основу личностного образования, при котором за студентом признается право 
Л. С. Ёлгина, И. М. Очиров. Философские основы научного мировоззрения в контексте личностно ориентированного образования

на самоопределение и самореализацию в познании окружающей действительности, на овладение способами ее гуманистического освоения. При этом особый акцент придается методам и приемам познавательной деятельности, выработке личностных отношений учащихся к изучаемым понятиям и явлениям.

Итак, основу мировоззренческих убеждений составляют понятия о вселенском пространстве, о взаимодействии биологической, социальной, технической систем, базирующихся на объективных законах природы, общества, человеческого мышления. Научные положения, устанавливая характер существенных, устойчивых связей между явлениями и объектами реального мира, выступают в качестве формы «всеобщности». Принимая понятие за единицу учебного содержания, всю программу обучения можно будет представить в качестве системы всеобщих, общих и частных идей и понятий, раскрывающих особенность существования и развития различных систем, их связей и соподчиненности. Учащиеся, усваивая сущность рассматриваемых закономерностей, понятий, убеждаются в проявлении закона о всеобщей связи явлений и процессов окружающей действительности, познают границы их действия.

Таким образом, формирование научного мировоззрения учащихся средствами личностно ориентированного образования осуществляется при условии, когда:

- из цели образования овладение студентами знаниями и умениями превращается в средство развития их индивидуальных способностей;

- студент, являясь субъектом процесса обучения и воспитания, становится субъектом мировоззренческого становления;

- виды взаимодействия преподавателя и студента базируются на «субъектсубъектной» основе, где каждый из участников сотрудничества выступает в качестве условия, средства и результата совместной деятельности;

- студенты определяют для себя личностно и социально значимые мировоззренческие идеи, составляющие основу их творческой деятельности;

- мировоззренческое образование в условиях разнообразной образовательной среды выступает важным фактором жизненного самоопределения и самореализации личности.

Итак, раскрывая основы научного мировоззрения в контексте личностноориентированного образования, мы выявили его составные части. Эти части соответствуют трем компонентам, каждый из которых представляет собой определенный комплекс:

- интеллектуальный, предусматривающий приобретение системы знаний и развитие методов научного мышления;

- личностный, характеризующийся формированием ценностных отношений, мотивацией, нравственной направленностью, оценочными суждениями;

- практический, включающий применение знаний в практической деятельности, руководство ими в поведении, реальной жизни.

Литература

1. Ёлгина Л. С. Фундаментализация образования в контексте устойчивого развития общества: сущность, концептуальные основания: диссертация на соискание ученой степени кандидата философских наук. Улан-Удэ, 2000. 154 с. Текст: непосредственный. 
2. Кон И. С. Психология старшеклассника. Изд. 2-е, доп. Москва, 1982. 207 с. Текст: непосредственный.

3. Гудинг Д. Мировоззрение (Для чего мы живем и каково наше место в мире). Москва: ДИА-пресс, 2000. 432 с. Текст: непосредственный.

4. Моисеев Н. Н. Человек и ноосфера. Москва: Молодая гвардия, 1990. 351 с. Текст: непосредственный.

5. Рогова Р. Развитие гуманистического мировоззрения и ценностных ориентаций личности / Российская академия образования, Институт развития личности. Москва, 1996. 144 с. Текст: непосредственный.

6. Сорокин П. Жизнеописание. Мировоззрение. Цитаты. Москва, 2007. 175 с. Текст: непосредственный.

7. Юшкевич П. С. Мировоззрение и мировоззрения. Очерки и характеристики. Москва: Либроком, 2011. 186 с. Текст: непосредственный.

Статья поступила в редакиию 15.04.2021; одобрена после рецензирования 28.04.2021; принята к публикащчии 11.05.2021.

\section{PHILOSOPHICAL BASIS FOR SCIENTIFIC WORLD VIEW IN THE CONTEXT OF PERSONALLY-CENTERED EDUCATION}

Larisa S. Elgina

Cand. Sci. (Philos.), A/Prof.,

Dorzhi Banzarov Buryat State University

24a Smolina St., Ulan-Ude 670000, Russia

elgina66@bk.ru

Innokentiy M. Ochirov

Senior Lecturer of Physical Education, Dorzhi Banzarov Buryat State University 24a Smolina St., Ulan-Ude 670000, Russia ochirov1966@gmail.ru

Abstract. The article deals with the scientific worldview as a spiritual, integrative, personal education orienting a person toward the creativity, decent way of life, comprehension of his own importance. The scientific worldview creates the necessary basis for designing a model of the individual's activity, helps him to realize the goals and understand the meaning of life, to find his place in society, to achieve his personal interests and capacity. The necessity of considering this problem is conditioned by a number of objective factors and trends.

We consider personality-centered education as a basis for the right to choose the subject content, methods of activity that ensure the humanization of education, the implementation of truly democratic foundations, and freedom of moral choice. All this creates new prerequisites for the development of persuasions, sustainable life orientations. Personalitycentered education is aimed at unlocking the individual capabilities and developing on their basis the universal human values, highly moral qualities of a person.

Keywords: personality, worldview, personality-centered education, humanistic orientation, values, ideals, life orientations 
Л. С. Ёлгина, И. М. Очиров. Философские основы научного мировоззрения в контексте личностно ориентированного образования

For citation

Elgina L. S., Ochirov I. M. Philosophical Basis for Scientific World View in the Context of Personally-Centered Education. Bulletin of Buryat State University. Philosophy. 2021; 2: 33-41 (In Russ.).

The article was submitted 15.04.2021; approved after reviewing 28.04.2021; accepted for publication 11.05.2021. 